\title{
LA SOCIEDAD CIVIL CHILPANCIGUEÑA EN LA CONTENCIÓN Y PREVENCIÓN DE LAS VIOLENCIAS. UN ESTUDIO DE CASO
}

\author{
Chilpancingueña civil society in the containment \\ and prevention of violence. A case study
}

Paula Valle de Bethencourt ${ }^{1}$

Fecha de recepción: 5 de septiembre de 2019

Fecha de aceptación: 9 de enero de 2020

1 - Nacionalidad: Española. Grado: Doctorado en Ciencias Sociales. Adscripcion: Universidad Autónoma de Guerrero. Correo electronico: paula.valle.bethencourt@gmail.com. (D) ORCID: http://orcid.org/0000-0003-1413-8863 


\section{Resumen}

Este artículo se interroga por el trabajo realizado por las organizaciones de la sociedad civil (OSC) para contener y prevenir las violencias en la capital del Estado de Guerrero, en Chilpancingo de los Bravo a través de la cohesión y la incrustación social. Es un trabajo mixto, pero pone el acento en lo cualitativo para profundizar en los significados que da la experiencia de las OSC. Argumenta que, a menudo, los trabajos contra las violencias son iniciales y que la desconfianza permea el grueso de las relaciones sociales y políticas, dificultando el trabajo de las OSC tanto con la ciudadanía y con el Estado, como entre las mismas organizaciones.

Palabras clave: Cohesión social, Incrustación social, Violencias, Chilpancingo.

\section{Abstract}

This article questions the work carried out by civil society organizations (CSOs) to contain and prevent violence, in the capital of the State of Guerrero, in Chilpancingo de los Bravo, through cohesion and social embedding. It is a mixed work, but it emphasizes the qualitative analysis to deepen into the meanings that the experience of CSOs gives. It argues that, often, the work against violence is initial and that mistrust permeates the bulk of social and political relations making it difficult for CSOs to work both with citizens and with the State, as well as among the organizations themselves.

Keywords: Social cohesion,Social embedding, Violence, Chilpancingo. 


\section{Introducción}

$\mathrm{E}$ ste artículo está enfocado en el marco de inseguridad y violencia que existe actualmente en el municipio de Chilpancingo de los Bravo, capital del estado de Guerrero. ${ }^{2}$ La finalidad es analizar, de manera descriptiva y exploratoria, el trabajo de las organizaciones de la sociedad civil (OSC) en Chilpancingo, respecto a la contención y prevención de las violencias. Uso dos categorías centrales para su análisis, que son la cohesión e incrustación sociales. Las categorías analíticas ayudan a observar y analizar la información empírica. ${ }^{3}$ Para conocer el trabajo de la sociedad civil realizo un análisis mixto (cuantitativo y cualitativo).

Parto de que la cohesión y la incrustación sociales pueden coadyuvar al Estado en sus actividades y prácticas para reducir y/o detener el clima de violencia que vive el país y, en concreto, en Chilpancingo. La cohesión social es entendida como una construcción de los lazos sociales de modo participativo e incluyente, de solidaridad y de ayuda. También se trata de mecanismos de protección que deriven en soluciones colectivas, negociadas y consensuadas para atender las necesidades cotidianas de la comunidad.

La incrustación (embedded) ${ }^{4}$, siguiendo a Karl Polanyi, refiere a la densidad y profundidad de las relaciones (Polanyi, 2012). Para este estudio consideré dos sentidos de la incrustación: 1) incrustación vertical que estudia la relación entre las organizaciones y la sociedad; y entre las organizaciones y el Estado; y 2) una incrustación horizontal que analiza la relación y profundidad entre las distintas organizaciones.

\section{Estado de la cuestión}

El estudio de la relación entre sociedad civil y violencias en Guerrero y, en específico, en Chilpancingo, no ha sido muy explorada por las investigaciones. El tipo de publicaciones sobre violencias y sociedad civil es variable y reciente. Sin embargo, ha sido estudiado el papel de las organizaciones en el medio ambiente (Aranda, 2008; Quintero y Domínguez, 2011; Niño, 2008). Estos trabajos se han centrado en las demandas, organizaciones y visibilización de problemas naturales como: a) la construcción de la Presa Hidroeléctrica La Parota, a 30 kms de Acapulco (Quintero y Domínguez, 2011); b) la detención del megaproyecto turístico en la Isla de la Roqueta Acaextremo, en Acapulco (Niño, 2008); y c) la construcción y detención de un nuevo muelle en Zihuatanejo que derivó en la Red de Organizaciones Ambientalistas de Zihuatanejo (ROGAZ) (Aranda, 2008).

Otros investigadores han analizado la organización y resolución de demandas desde la policía comunitaria de Guerrero (Martínez, 2012; Sánchez y Rangel, 2008). La policía comunitaria no es considerada propiamente sociedad civil, sino, más bien, un "mecanismo de justicia alterno (...) para combatir la inseguridad pública y la delincuencia organizada” (Sánchez y Rangel, 2008: 89), que sirve para recuperar

2- Esta investigación forma parte del proyecto "Ciudadanía y violencia urbana en Guerrero", número 1200 de CONACYT.

3- Este trabajo de diagnóstico se realizó para Acapulco, ver Valle (2019); del resultado de este trabajo y del realizado en Acapulco, realicé un análisis comparativo entre Acapulco y Chilpancingo en Valle (en prensa).

4- Este término ha sido traducido también como "arraigo". También la sociología relacional ha usado el término embedded para hablar de incrustación. 
el poder por parte de los ciudadanos en la "organización" e "impartición de justicia" a los problemas de violencia que enfrentan (Martínez, 2012).

Para los autores que estudian sociedad civil, es vista como la protagonista en tejer redes de apoyo abordadas desde temáticas aparentemente diferentes: por ejemplo, las organizaciones participan en que los ciudadanos se apropien de los espacios para organizarse, visibilizar y apoyar las demandas de sectores vulnerados: es el caso de los colectivos de mujeres e indígenas en Guerrero (Aguirre, 2004; Canabal, s/f; 2003; 2015).

Algunos autores han investigado la percepción (Triana, 2017a; Valle, 2019) y expansión de la violencia (Agren, 2015; Cattan, 2011; Gutiérrez, 2007). Respecto a la percepción de la violencia, Triana (2017a) y Valle (2019) analizan la misma encuesta realizada a 831 encuestados, en los polígonos señalados por el Programa Nacional de Prevención del Delito (PRONAPRED), como los más peligrosos en el municipio de Acapulco (Petaquillas, Renacimiento, Zapata, Progreso y Jardín). Si bien analizan la percepción de la violencia, lo hacen desde actores diferentes, Triana (2017a) estudia las instituciones de impartición de justicia, concluyendo que existe menos confianza en la policía municipal y estatal y algo mayor en la federal. Valle (2019), por su parte, analiza el papel de las OSC respecto al fenómeno de la violencia y concluye que el trabajo de las organizaciones en estos temas es aún incipiente y que el nivel asociativo es bajo.

Agren (2015) y Cattan (2011) abordan el modo en que la expansión de esta violencia repercute en el turismo extranjero, por ejemplo, en Acapulco (Cattan, 2011; Llana, 2006). Por su parte, Gutiérrez aborda cómo la contaminación simbólica se propaga, al mostrar cabezas decapitadas en espacios públicos como formas de violencia sociocultural (Gutiérrez, 2007).

Ríos (2008), desde su perspectiva, sostiene que la percepción de la violencia como verbal y física, referente a violaciones, asesinatos, etc., está normalizada en Guerrero. Llana (2006) y Rivera (2015) abordan el fenómeno de expansión de la violencia de ciudades fronterizas, caracterizadas por ser violentas. Llana (2006) se centra en el trasvase de la violencia hacia Acapulco. Rivera analiza la expansión de Ciudad Juárez, a la que denomina "ciudad asesina", hacia otras ciudades como Monterrey, Cuernavaca, Veracruz. Se trata de un aumento de la violencia en espacios que no eran considerados en principio violentos, por dos razones: 1) la capacidad estatal o la falta de ella para hacer frente al problema, y 2) el aumento y permanencia de los cárteles de drogas ilícitas.

Ley (2014) es la única autora que trata el tema de la violencia en correlación con la participación electoral. La autora diseñó una encuesta postelectoral aplicada en Arcelia (Guerrero) y Pajuacarán (Michoacán) a víctimas que han sufrido violencia del crimen organizado. También creó un banco de datos de periódicos de protestas contra el crimen en México durante 2006-2012. El resultado de su investigación indica que las actividades violentas inhiben a las víctimas de participar en votar, asistir a marchas, etc.

Gamlin y Hawkes (2018) posicionan a los hombres como las principales víctimas de la violencia en México. En su estudio basado en estadísticas del INEGI, señalan que el $88 \%{ }^{5}$ de víctimas son el resultado

5- Conocer la causa última por la que el 12\% no percibe inseguridad es casi imposible en un estudio de Ciencias Sociales. Habría que hacer un estudio al respecto para conocer a qué se debe que este porcentaje responda negativamente a la percepción de inseguridad, por ejemplo, mediante modelos de regresión o cruce de variables. Otra manera de conocer el por qué el 12\% sería preguntando en la encuesta, las razones del por qué no percibe inseguridad. Sin embargo, normalmente las encuestas remarcan los datos más significativos. Una última manera de conocer este $12 \%$ sería mediante un estudio cuasi-experimental, para ello, podríamos comparar dos casos que sean semejantes, es decir, que los porcentajes sean parecidos y que sus contextos sean similares, en condiciones sociales, económicas, educativas, manteniendo el resto de variables constantes, lo que se conoce como Ceteris Paribus. Así, podríamos analizar si con tales variables independientes $(\mathrm{X} 1+\mathrm{X} 2+\mathrm{X} 3 \ldots)$, como nivel educativo, clase social, género, etc., se produce la percepción de seguridad (Y). Pero hay varios problemas metodológicos que podrían afectar, uno de ellos es la colinealidad que es el modo en el que se afectan entre las mismas variables independientes. Para conocer más sobre los estudios cuasiexperimentales en investigaciones cualitativas puede consultarse (King et al., 2000). 
de homicidios. Se trata de hombres que matan a otros hombres. ${ }^{6}$ En este sentido, también se ha estudiado la relación entre el aumento de homicidios y crecimiento del crimen organizado por el narcotráfico (Figueroa y Martínez, 2013; Gamlin y Hawkes, 2018). Estos autores abordan cómo el modelo económico neoliberal es causa de la violencia y escasez de oportunidades de trabajo en México, especialmente en el suroeste del país (Guerrero, Oaxaca, Chiapas). En sentido contrario, Aguirre (2004) y Canabal (s/f; 2003; 2015) indican que las mujeres son las más vulneradas, al ser víctimas de la violencia por cuestiones de género y de sufrir más feminicidios (crímenes de odio por el hecho de ser mujeres). ${ }^{7}$

También ha sido abordado el vínculo entre cohesión social y las violencias (De León y Velásquez, 2012; Jasso, 2013; Lunecke y Ruiz, 2007; Serrano y Modrego, 2012). Aunque el trabajo que realiza la sociedad civil, desde la cohesión social, para prevenir y contener las violencias ha sido menos explorada. En general, se trata de estudios de caso, en ciudades, por los datos sobre violencia urbana (Aziz, 2011; Castillo, 2009; González, 2009; Serbin, 2008; Serrano y Modrego, 2012; Valle, 2019; Zúñiga, 2007).

En un texto más teórico, Andrés Serbin (2008) denomina "violencia social" a aquella producida por crimen organizado, pandillas, homicidios, etc. Para este autor, esta violencia se genera en zonas urbanas y entre los hombres. El autor distingue dos tipos de trabajos de las organizaciones de la sociedad civil para procurar la paz: por un lado, a) aquel trabajo llevado a cabo por intelectuales y académicos preocupados por temas de militarización, defensa y seguridad, donde están también los organismos intergubernamentales (como la ONU y la OEA) para la procuración de paz y la gestión de crisis humanitaria. Estos actores tienen mayor capacidad analítica e interlocución con los distintos organismos y organizaciones regionales y gobierno; y por otro lado, b) se encuentran las organizaciones locales, que muestran reacciones frente a la violencia y la criminalidad. ${ }^{8}$ Las organizaciones se dirigen a los gobiernos locales y nacionales y buscan soluciones para la violencia cotidiana. Los dos tipos de actores (a y b), según Serbin, buscan la paz o una cultura de paz.

En una línea parecida, De León y Velásquez (2012) indican que la sociedad civil queda en mitad del conflicto entre el Estado y el crimen organizado, pero por su falta de organización no siempre es posible prevenir, contener o actuar frente a las violencias. Algunos autores remarcan que la relación entre la percepción de seguridad y la desconfianza es multicausal: está condicionada por los homicidios, la pobreza, la desigualdad, etc. (Valle, en prensa; De León y Velásquez, 2012; Lunecke y Ruiz, 2007).

Siguiendo la propuesta metodológica de Jusidman et al. (2011), que se plantea en este artículo y que se encuentra más abajo, Castillo (2009) y González (2009) realizan el diagnóstico, en Ciudad Juárez y Tijuana respectivamente. Para Castillo (2009), al igual que Aziz (2011), en Ciudad Juárez el tejido social es fuerte, por la lucha en contra de los feminicidios, que inició en la década de los noventa y que ha permanecido en las siguientes décadas. Además, Castillo añade que la sociedad civil no siempre puede responder a las demandas por falta de recursos económicos y la dificultad de sostener los proyectos en el tiempo.

6- Esta aclaración de que sean hombres que matan a otros hombres la establecen las autoras. En general, las estadísticas dentro y fuera de México muestran que la mayoría de homicidios son cometidos por hombres.

7- La diferencia entre feminicidios y homicidios dolosos contra las mujeres radica en que los primeros son crímenes realizados con odio por el hecho de ser mujer, mientras que los segundos pueden ser asesinatos, pero no por el hecho de ser mujeres. Así lo establece, en el artículo 21, la Ley General de Acceso de las Mujeres a una Vida Libre de Violencia (LGAMVLV), publicada por el Diario Oficial de la Federación el 1 de febrero de 2007 (Cámara de Diputados del H. Congreso de la Unión, 2018). Esto es importante porque la aplicación de la ley supone una tipificación penal, protocolos y presupuestos específicos en el caso de que sean feminicidios.

8- Esta investigación se centra en las organizaciones locales. 
González realiza un estudio de diagnóstico en Tijuana y concluye que el tejido asociativo es bajo para temas de violencias, debido al deterioro de los lazos comunitarios y la poca cultura participativa, que está "poco comprometida, sin una visión y metas a mediano y largo plazo" (González, 2009: 143). Esta idea de que existe poca participación, en contextos de violencias, es compartida por varios autores que, a su vez, remarcan que la baja participación produce aislamiento y poco desarrollo comunitario y calidad de vida (González, 2009; Herrera-Lasso, 2012; Lunecke y Ruiz, 2007; Valle, 2019).

Para González (2009) y Castillo (2009): 1) el crimen organizado puede ser un espacio de "oportunidades económicas" y de "refugios familiares" para los jóvenes que están excluidos por pobreza, desigualdad, etc., y 2) resaltan la capacidad de las organizaciones de mujeres o feministas para abordar temáticas de la agenda en torno a temas de violencia. Para Ciudad Juárez, en la participación en la "Comisión para Prevenir y Erradicar la Violencia", ahora a nivel nacional, y en la "Fiscalía Especializada en Delitos Violentos contra las Mujeres" (Castillo, 2009); en Tijuana, con el "Movimiento Urbano Popular” (González, 2009).

Hasta el momento y a pesar de estar entre las ciudades más peligrosas del país, no existen muchas investigaciones que traten de manera conjunta el papel de las organizaciones de la sociedad civil respecto a las violencias y sus prevenciones en Chilpancingo.

\section{Las violencias en Guerrero como problema de investigación}

De acuerdo con el último estudio realizado por Seguridad, Justicia y Paz sobre "La violencia en los municipios 2018", Chilpancingo ocupa el décimo lugar con mayor percepción de violencia en México, de un total de 234 municipios. En la última "Encuesta Nacional de Seguridad Pública Urbana” del INEGI publicada en septiembre de 2019, la percepción social sobre inseguridad pública en Chilpancingo es de 88.3\%, mientras que en Acapulco es de 89.9\% (INEGI, 2019: 2).

Según el Índice de violencia Municipal', elaborado por Seguridad, Justicia y Paz, dentro de los primeros once puestos, cuatro de los municipios son guerrerenses: Acapulco ( $7^{\circ}$ lugar), Zihuatanejo ( $9^{\circ}$ lugar), Chilpancingo ( $10^{\circ}$ lugar) e Iguala ( $11^{\circ}$ lugar) (Seguridad, Justicia y Paz, 2019: 22). Dentro de este índice sobresalen dos puntajes parciales que son altos respecto a los otros municipios guerrerenses: el de secuestros con un $0.81^{10}$, y el correspondiente a lesiones con un $4.76^{11}$ (Seguridad, Justicia y Paz, 2019: 22). El puntaje más alto en este índice, para Chilpancingo, corresponde al de homicidios, con el 51.54. Según Muggah y Aguirre, Chilpancingo tiene una tasa de homicidios de $88.1^{12}$, para el año 2016, Chilpancingo ocupó el quinto lugar en el ranking de las 50 ciudades con mayor número de homicidios a nivel mundial (Muggah y Aguirre, 2018: 6).

9- Estos datos corresponden a un índice, los ítems que se valoran tienen un peso específico, establecido por el propio informe. Los ítems y sus pesos relativos son: "homicidio" (55), "secuestro" (22), "violación" (13), "lesiones" (4), "robo con violencia (RCV)" (3), "extorsión" (3), la sumatoria de estos puntajes parciales si todos llegarán a su máxima puntuación daría 100 , pero no se trata de un porcentaje. La relevancia de este índice no es el peso relativo de cada uno de los delitos, sino su comparación con otros municipios.

10- Está por encima de Acapulco (0.44) y Zihuatanejo (0.67) en secuestros, ocupan el séptimo y noveno lugar respectivamente.

11- Los puntajes parciales para "Lesiones" son de 4.53 para Acapulco y 2.48 en Zihuatanejo.

12- Este dato es una tasa calculada por cada100,000 habitantes. Por delante de Chilpancingo, que es considerada una de las cinco primeras ciudades con más tasa de homicidios, se encuentran: San Salvador (1er. lugar), Acapulco de Juárez (2do. lugar), San Pedro Sula (3er. lugar), Soyapango (4to. lugar). 
En el "Informe de Grupo de Trabajo para atender la solicitud de Alerta de Violencia de Género (AVG) contra las Mujeres en ocho municipios del Estado de Guerrero (2015)”, de 2010 a 2015 se cometieron 901 feminicidios en Guerrero, "el 47.84\% se concentra en el municipio de Acapulco, seguido por Iguala con el 5.44\%, y en tercer lugar el 4.99\% en Chilpancingo" (Vilchis, Díaz, Soto et al., 2016: 21).

Por contención de las violencias, entiendo todas las actividades encaminadas a aminorar las violencias en cuanto a sus prácticas y actividades, así como proteger, acompañar, derivar a otras instituciones ${ }^{13} \mathrm{y}$ fomentar el cuidado de la vida. Por prevención de las violencias, siguiendo a Triana (2017b) entiendo que:

consiste en acciones enmarcadas en la legitimidad legal pero ajenas a la sanción penal que, en el ámbito de lo público, conducen a disminuir la probabilidad de ocurrencia del delito en el corto, mediano y largo plazo, producto de la disminución simultánea de delincuentes, delitos cometidos, víctimas y daños ocasionados, a través de medidas que atienden factores de riesgo y protección de carácter: individual, social, comunitario y focalizado (Triana, 2017b: 99).

Parto del presupuesto de que la cohesión y la incrustación social pueden coadyuvar al Estado en sus actividades y prácticas para aminorar y/o detener el clima de violencias que vive el país y, en concreto, en Chilpancingo (Guerrero). La cohesión social es entendida como una construcción participativa e incluyente de los lazos sociales de solidaridad y de ayuda. También se trata de mecanismos de protección que deriven en soluciones colectivas, negociadas y consensuadas para atender las necesidades cotidianas de la comunidad. La incrustación, siguiendo a Karl Polanyi (2012), refiere a la densidad y profundidad de las relaciones.

Siguiendo a Jusidman, Ruvalcaba, Marín et al. (2011), denomino "violencias" en plural al conjunto de fenómenos que debe enfrentar la sociedad civil en su trabajo (i.e. social, cultural, de género, económica, racial, homicidios, delito común, extorsión, secuestro, feminicidios, etc.), porque a menudo confluyen distintas violencias que la sociedad civil trabaja por contener y prevenir. En cierto sentido, esta investigación parte de la propuesta metodológica sobre el diagnóstico territorial de las causas sociales de las violencias elaborado por Clara Jusidman et al., en específico, la dedicada a las organizaciones de la sociedad civil. Si bien añado otras dimensiones y aspectos a su análisis, este trabajo buscó ser una réplica del diagnóstico, aplicado a la situación de las organizaciones de la sociedad civil en Chilpancingo.

Este trabajo tiene el propósito de realizar un diagnóstico desde el punto de vista de las organizaciones de la sociedad civil (OSC) respecto a la cohesión e incrustación sociales en la contención y prevención de violencias, en Chilpancingo de los Bravo, capital del estado de Guerrero. La pregunta que guio la investigación fue: ¿de qué manera las organizaciones de la sociedad civil contienen y previenen las violencias mediante la cohesión e incrustación sociales, en Chilpancingo? ${ }^{14}$

El argumento que guía el trabajo consiste en que las OSC realizan un trabajo incipiente o inicial respecto a la cohesión y la incrustación social para la contención y la prevención de las violencias. En general, encuentran grandes dificultades para construir mecanismos de inclusión y de protección mutua que coadyuven en la contención y prevención de las violencias por el miedo, la desconfianza y la normalización

13- Las organizaciones, como se comentará más adelante en el análisis, hacen un trabajo de canalización o derivación al sistema judicial, legal, médico y psicológico en víctimas de violencias, por no considerarse preparadas para atender estos temas.

14- Esta pregunta ya ha sido planteada para otros trabajos de mi autoría en Valle (2019) y Valle (en prensa). 
de las violencias. Asimismo, la densidad de las relaciones de la sociedad civil (incrustación social) es aún baja respecto del Estado y también entre las mismas organizaciones. Sin embargo, existe, en cierto sentido, cohesión y también densidad o profundidad de las relaciones sociales, ante temas coyunturales que ocupan la agenda política como la Alerta de Violencia de Género (AVG).

\section{Incrustación, cohesión social, categorías de análisis}

Mi presupuesto parte de que las actividades de las OSC, cuando están incrustadas con la comunidad, con el Estado y con otras organizaciones, así como cuando desarrollan mecanismos de cohesión, pueden funcionar como instancias de contención y prevención de las violencias. En sentido contrario, si sus actividades no están incrustadas y, además, no coadyuvan en la cohesión social, éstas no pueden funcionar como instancias de prevención y contención de las violencias.

Siguiendo el diagnóstico de Jusidman et al. (2011), las organizaciones de la sociedad civil y redes sociales son aquellas como culturales, deportivas, sociales, etc. En esta investigación se han analizado las organizaciones de la sociedad civil. También se incluyen, en menor medida, las redes familiares y entre localidades (aquellas que establecen relaciones con otros municipios, estados y/o con el extranjero). En mi estudio confluyen, bajo el rótulo de "organizaciones de la sociedad civil", ejemplos de los diversos tipos de organizaciones municipales.

En este sentido, se trata de analizar, en primer lugar, cuántas son (número) y qué hacen (actividades). En segundo lugar, cómo se vinculan con los habitantes y entre ellas mismas, bajo la presunción de que mientras el arraigo de las organizaciones sea profundo en la población y más estrechas sean las relaciones de las organizaciones entre sí, se dará una densidad más profunda del tejido organizativo o asociativo municipal. Siguiendo a Karl Polanyi, a esta interpenetración vertical en relación con la comunidad y el Estado; y horizontal entre las organizaciones, lo llamé incrustación. ${ }^{15}$

En cuanto a la cohesión social, cabe señalar que no solo son las políticas públicas y la gestión gubernamental orientadas a la "procura existencial" (Forsthoff, 2015; 2013) ${ }^{16}$, sino también las organizaciones sociales, civiles, culturales y comunitarias ${ }^{17}$ pueden cumplir una función decisiva para la cohesión, es decir, para la inclusión y participación de los ciudadanos en los asuntos públicos y la defensa de sus intereses, en el marco de una democracia local (Olvera, 2007). Existe una nueva perspectiva de la cohesión social en América Latina que pone el acento en la necesidad de construcción de ciudadanía y derechos sociales, como un horizonte de posibilidad para la construcción de instituciones y derechos universales (Barba, 2011: 68). En este sentido, este trabajo interroga la posibilidad

15- Para ampliar sobre el concepto de incrustación. Ver Polanyi (2012).

16- Para la Comisión Económica para América Latina y el Caribe, se trata de los "elementos objetivos" que constituyen el concepto de cohesión social: "empleo, los sistemas educacionales, la titularidad de derechos y las políticas de fomento a la equidad, el bienestar y la protección social” (CEPAL, 2007: 17).

17- Esta tradición de conocer los mecanismos que realiza la sociedad civil para favorecer la cohesión se inserta en la concepción estadounidense, a diferencia de la europea que parte de que ésta es propiciada por el Estado. Si bien este trabajo trata de responder a ambas instituciones (Estado y sociedad civil), se apoya más en el último. Para ver más sobre este debate en América Latina puede consultar Sorj y Tironi (2007). 
de construcciones de cohesión social desde las organizaciones de la sociedad civil locales. ${ }^{18}$

La cohesión social es entendida no como un concepto armónico, sino como los mecanismos posibles que desarrollan las organizaciones para integrar e incluir, en algún sentido, aquello que parece estar excluido (por pobreza, violencias, desigualdad, género, raza, etc.). La cohesión social es, entonces, el conjunto de características en las relaciones o vínculos sociales que posibilitan el sentido de pertenencia social, a través de la confianza en las instituciones y en la sociedad. En relación a las violencias, las organizaciones, a través de la intermediación ${ }^{19}$ y la incrustación, podrían evitar y solucionar conflictos, mediante unos niveles mínimos de consenso y la inclusión de los excluidos, ayudando en el involucramiento participativo de la ciudadanía, difundiendo la cultura de la paz y los servicios sociales que atienden problemas cotidianos que, por distintos motivos, el gobierno no cubre (por ejemplo, opciones de esparcimiento en el tiempo libre para niños, niñas y jóvenes). Cuando sus actividades obtienen resultados satisfactorios ("buenas prácticas"), éstas constituyen experiencias ejemplares que pueden ser replicadas en otras áreas, zonas o sectores sociales problemáticos. Analizar la cohesión social en un contexto de violencia, puede aportar ciertas especificidades que en otros lugares no ocurren sobre el modo en el que se producen estos mecanismos de solidaridad y confianza, debido a que la cohesión social no es sólo un fenómeno a estudiar, sino también a construir (Sorj y Tironi, 2007).

\section{Cuestiones metodológicas}

Tuve acceso a la base de datos de la Encuesta Estatal sobre Calidad de la Ciudadanía en Guerrero (EECCG), realizada en 2016 por el Instituto Electoral y de Participación Ciudadana del Estado de Guerrero (IEPC-Gro) y el Instituto Internacional de Estudios Políticos Avanzados Ignacio Manuel Altamirano (IIEPA-IMA). A partir de la base y de su ordenamiento, realicé un análisis de estadística descriptiva. El muestreo de esta encuesta fue aleatorio polietápico y estratificado, con representatividad a nivel estatal y en cada una de las regiones (IEPC-Gro e IIEPA-IMA, 2017). Los encuestados fueron 375 para Chilpancingo de los Bravo. ${ }^{20}$

En este trabajo se realiza un análisis descriptivo y exploratorio sobre los mecanismos que ejerce la sociedad civil respecto a la cohesión e incrustación sociales. La finalidad de este estudio es comprender y profundizar en los significados que dan los propios entrevistados, como actores clave que hacen de intermediarios entre sociedad y Estado. Se trata de un análisis comprehensivo y principalmente cualitativo, aunque se apoya en datos cuantitativos a modo de "radiografía" de una situación que permita posteriormente, con los relatos, una mayor profundización. Para ello, se realizaron 34 entrevistas semiestructuradas. ${ }^{21}$

18- Para la CEPAL se trata de los elementos subjetivos del concepto de cohesión social, a saber: "la confianza en las instituciones, el capital social, el sentido de pertenencia y la solidaridad, la aceptación de normas de convivencia y la disposición de participar en espacios de deliberación en proyectos colectivos" (CEPAL, 2007: 17).

19- Para conocer más sobre el papel de las OSC como intermediarias, puede consultarse Ansolabehere y Valle (2017).

20- De la EECCG, me centré en las preguntas: 1) "En términos generales ¿Cree usted que se puede confiar o no se puede confiar en la mayoría de las personas?”; Confianza en las instituciones: Por favor dígame ¿cuánta confianza tiene en ONG's, Iglesias, Organizaciones vecinales, Organizaciones de adicciones (AA), maestros, gobierno federal, estatal, municipal, policía?

21- Se realizaron 34 entrevistas por llegar a la "saturación teórica" que es el momento en el que la información comienza a repetirse Valles (1999). 
El análisis realizado en este trabajo es de contenido. Se trata de una técnica de análisis heterogénea, con varias aristas, sin embargo, en este estudio me centré en describir "las semejanzas y diferencias" (Fernández, 2002: 37) de las organizaciones para poder "Identificar actitudes, creencias, deseos, valores, centros de interés, objetivos, metas, etc., de personas, grupos, organizaciones” (Fernández, 2002: 36). El análisis de contenido es útil para analizar una gran cantidad de información (López, 2002: 168).

La forma de contactar con las organizaciones fue a través del Sistema de Información del Registro Federal de las Organizaciones de la Sociedad Civil, a cargo de la Comisión de Fomento de las Actividades de las Organizaciones de la Sociedad Civil, del Instituto Nacional de Desarrollo Social (INDESOL). La ruta de búsqueda fue la siguiente: 1) ingresar a https://www.corresponsabilidad.gob.mx/\#, 2) seleccionar "Buscador de OSC", 3) en "Criterios de Búsqueda Avanzada" seleccionar "Mostrar campos de búsqueda avanzada". Dentro de la base nacional, se seleccionó "Guerrero" en el campo "Entidad Federativa" y "Chilpancingo" en el de "municipio". En este directorio están las organizaciones de la sociedad civil de carácter formal, con "Clave Única de Inscripción" (CLUNI), que están registradas o que lo estuvieron en el pasado. Desde esa base de datos, se configuró un directorio de las organizaciones, que se fue enriqueciendo con otras organizaciones que eran contactadas, mediante la "técnica de la bola de nieve" y que no estaban necesariamente legalizadas. ${ }^{22}$ De este modo, configuré un directorio con 141 organizaciones legales y no legales.

En un primer momento, la intención era entrevistar a las OSC que estuvieran o que trabajaran en los polígonos de las colonias CNOP y Obrera, porque estos polígonos eran los seleccionados por el PRONAPRED como focos de atención. Así, el gobierno federal destinaba recursos a dichos polígonos. Sin embargo, a medida que se fue avanzando en las entrevistas, fue siendo cada vez más evidente que la mayoría de las OSC no habían recibido estos recursos ni conocían los programas que comprendía el PRONAPRED. Sólo cuatro de las 34 entrevistadas habían recibido recursos de PRONAPRED. No obstante, no lo hicieron como organización, sino a título individual. Esto sumado a la poca transparencia del programa para la implementación de su política pública y, por tanto, de los recursos y con la finalidad de comprender el objetivo de esta investigación el modo en que las OSC trabajan en temas de contención y prevención de las violencias en Chilpancingo, se amplió a toda la ciudad, a partir de la entrevista 15. Si bien se siguió preguntando en todas las entrevistas por el PRONAPRED, no fue un criterio de selección el haber participado en este programa. Esta situación hizo que las entrevistas fueran realizadas en un período largo de tiempo, de abril de 2018 a enero de $2019 .^{23}$

A pesar de que no fue un criterio de selección, es un hallazgo de la investigación que no lleguen a las OSC los recursos del PRONAPRED, por lo que se ha decidido mapear geo-referencialmente, con la ayuda del programa ArcGis, el trabajo o la ausencia del mismo que realizan las organizaciones en dichos polígonos, así como su localización. Así, se establecieron dos criterios: 1) el domicilio postal donde se encuentran las organizaciones; y 2) los polígonos donde realizan el trabajo (o su ausencia) en los polígonos.

Para realizar las entrevistas, contacté con los representantes de las organizaciones vía telefónica, correo electrónico y redes sociales (principalmente Facebook y WhatsApp). Siempre que fue posible primero

22- La técnica de bola de nieve es un recurso muy utilizado en investigación cualitativa, específicamente, en la realización de entrevistas. Esta consiste en que las organizaciones entrevistadas faciliten al entrevistador datos para contactar a posibles nuevos entrevistados. Por ejemplo, en este trabajo, la 17 me contactó con la 26; la 9 con la 24; la 31 a la 34 ; y la 22 y 27 me sugirieron entrevistar a la 19.

23- Para el diagnóstico de Acapulco, el período en el que se concluyeron las 34 entrevistas fueron tres meses. 
llamé por teléfono. Me presentaba diciendo mi nombre y que trabajaba en la Universidad Autónoma de Guerrero. Esta forma de presentarme fue intencionada, buscaba generar confianza con mi interlocutor. Confirmaba que estuviera siendo atendida por el representante de la organización y, si había oportunidad inmediata, procedía a confirmar o completar y/o actualizar datos del directorio. Si no había respuesta en el primer intento de contacto telefónico, lo repetía de 3 a 4 veces más en días consecutivos. Si no lograba contactarme mediante la llamada, me dirigía por mail con una carta de presentación donde explicaba los objetivos del estudio, quién era, la página Web de la universidad donde aparece mi perfil y el número telefónico donde podían encontrarme. En caso de no conseguir respuesta, les mandaba un mensaje con la misma información, pero mediante la aplicación de celular WhatsApp. Esto lo hice así, porque podían ver que era una persona real con una foto. Si todo lo anterior fallaba, enviaba mensajes en Facebook, principalmente para las organizaciones sin CLUNI.

En varios casos hubo resistencia incluso a tomar la llamada, al mencionarles que la investigación era sobre violencias urbanas. Otros más solicitaban más información también por correo electrónico, por lo que era necesario llamarlos nuevamente. Algunas organizaciones habían trabajado sobre el tema, pero no específicamente en la CNOP o en La Obrera. Sin embargo, una vez accedían a responder las preguntas de la entrevista se mostraron dispuestos y accesibles. Todas las entrevistas fueron grabadas con consentimiento explícito por parte del entrevistado.

El promedio de tiempo de todas las entrevistas fue de 50 minutos. La entrevista más larga duró dos horas y la más corta fue de 31 minutos. Un dato añadido, que surgió de las llamadas a todas las organizaciones, fue que once de las 34 entrevistas (E3, E8, E11, E14, E19, E22, E23, E26, E27, E28 y E34) se dedican a la atención, prevención y acompañamiento en la violencia contra las mujeres. Estas organizaciones tienen como principal objetivo el empoderamiento y capacitación para las mujeres y coincide con la instauración de la Alerta de Violencia de Género en Guerrero (AVGG), que será analizado más adelante. En Chilpancingo, por ser la capital del estado, existe un movimiento de organizaciones que se articularon, principalmente, para exigir al Estado la necesidad de declarar la Alerta. Organizaciones como la E8, E19, E22, E23, E27 y E34 iniciaron, promovieron y participaron en el proceso de la solicitud de la Alerta Contra la Violencia de Género en Guerrero. ${ }^{24}$

\section{Testimonios de las organizaciones civiles: análisis}

\subsection{Incrustación organizativa y cohesión social}

En el siguiente cuadro se muestra la distribución de la sociedad civil en el municipio de Chilpancingo. La sociedad civil se concentra en aquellas colonias (polígonos) en las que el gobierno estatal, a través de PRONAPRED, ha puesto mayor atención y financiamiento, a saber, la Obrera y CNOP.

24- Según el Observatorio Ciudadano Nacional del Feminicidio, la solicitud de la Alerta de Violencia de Género contra las Mujeres fue propuesta en junio de 2016 y aceptada por la CONAVIM un año después (junio de 2017), "a pesar de que el estado de Guerrero fue la primera entidad federativa en tipificar el feminicidio (desde 2010) (...) de ese año a 2017 sólo $8 \%$ de los 544 asesinatos de mujeres se han investigado como feminicidio; es decir, el número de investigaciones ha disminuido desde su homologación al tipo penal" (OCNF, 2018: 82). 
Mapa 1. Distribución y penetración de las organizaciones de la sociedad civil en Chilpancingo
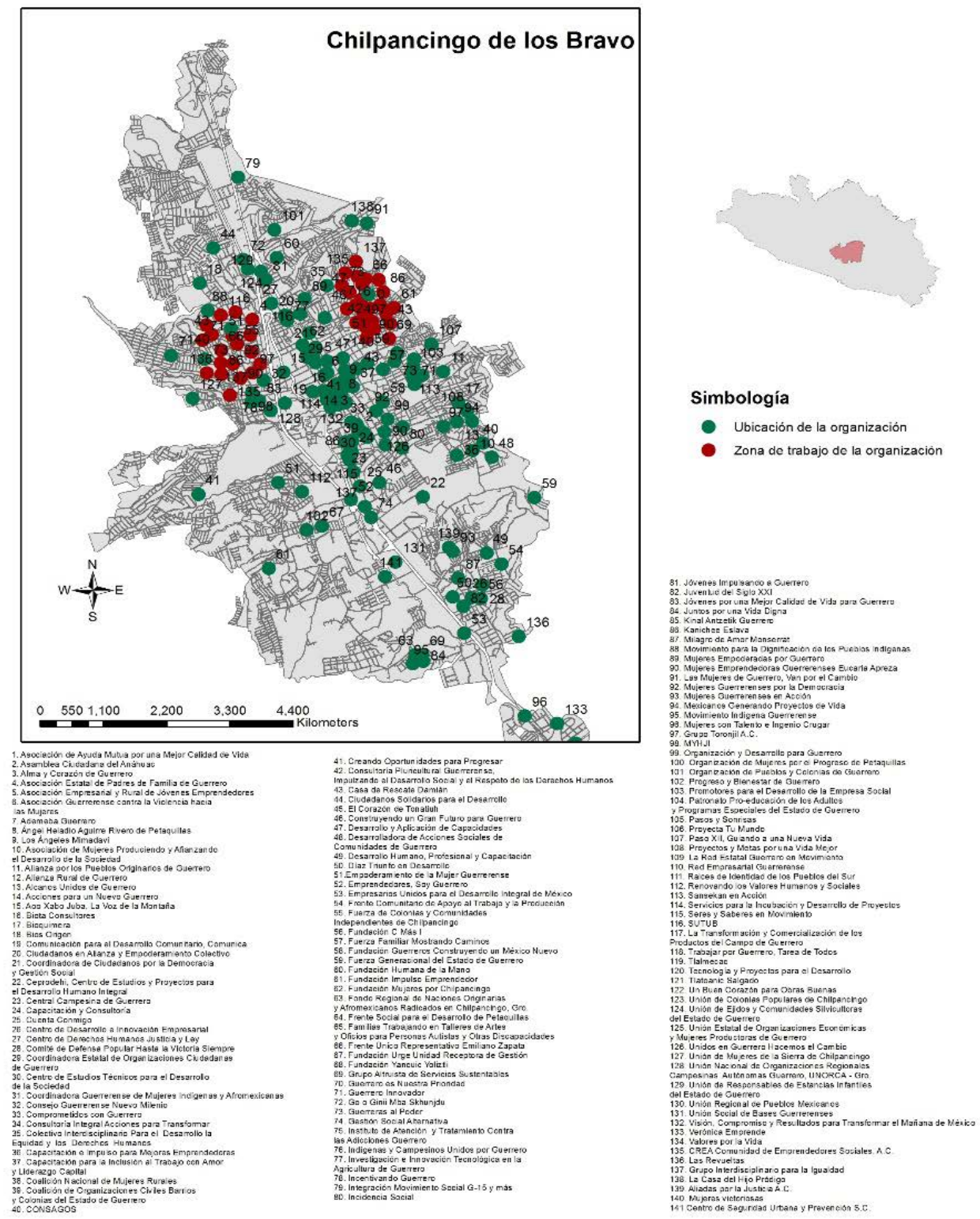

Fuente: elaboración propia a partir de los datos del INDESOL y entrevistados

El lado superior-izquierdo (noroeste) corresponde al polígono La Obrera, mientras que el superior-derecho (noreste) es la CNOP. Estos dos polígonos son diferentes, aunque coinciden en estar en los márgenes de la ciudad. Son colonias con falta de alumbrado público, agua potable, drenaje, etc., son consideradas menos urbanizadas que otras partes de Chilpancingo. La CNOP está constituida por población migrante y mayormente pobre o con dificultades económicas "es una colonia periférica, suburbana (...) siempre se ha sabido que 
tienen ciertos focos de personas de la Sierra, de situaciones, pero que estaba tranquilo. Ahorita se está viendo que se les están aniquilando" (E3) ${ }^{25}$, mientras que La Obrera tiene grupos delincuenciales y de narcotráfico en su interior "la Obrera es un poquito más peligroso en cuestiones de violencia" (E11), "la colonia Obrera tiene un mayor índice en todos los aspectos negativos: violencia, alcoholismo, drogadicción, trata" (E13).

Si bien hay varias organizaciones de las entrevistadas que trabajan en los polígonos ${ }^{26}$, es común que el lugar de trabajo de las organizaciones se encuentre en otras zonas de Chilpancingo, en concreto, en la zona centro. Por la peligrosidad de los territorios, en muchas ocasiones, las organizaciones tienen dificultades para adentrarse en los mismos y poder desarrollar un trabajo con sus habitantes: "Una percepción casi palpable de inseguridad pública: si ya lograste entrar a las colonias, moverte en ellas ya es bastante difícil sin sentir que te están siguiendo o sentir que te están monitoreando o que hay gente que está vigilando qué es lo que haces. Una restricción de los horarios en los que puedes andar en estas colonias" (E8). ${ }^{27}$ A veces, deben establecer redes de seguridad entre las propias organizaciones, o establecen horarios para entrar y salir de las colonias (E14).

Como mencioné más arriba, la cohesión social es entendida en este trabajo como los mecanismos incluyentes y participativos de ayuda mutua y protección que resuelven, de un modo más o menos consensuado y negociado, necesidades comunitarias. Desde la perspectiva de las organizaciones de la sociedad civil de Chilpancingo que formaron parte de este diagnóstico, la construcción, mantenimiento y expansión de tales mecanismos constituye su propia razón de ser, más allá de las diferencias que éstas puedan tener en cuanto a sus objetivos particulares. Al ser interrogadas, suelen considerar que es una tarea compartida con las autoridades gubernamentales, en los distintos niveles de gobierno.

Si bien inician trabajos de ayuda mutua y protección con las violencias, para dos casos específicos, como se verá más adelante, el establecimiento de redes, el trabajo en conjunto y la densidad de los lazos se observa en 1) el caso de la AVGG, promovido por la propia sociedad civil; y 2) para los trabajos con recursos de PRONAPRED ejecutados por la sociedad civil y realizados en los polígonos de la CNOP y la Obrera. Para el resto de violencias y territorios, este trabajo conjunto aún se presenta más como un deseo que como una realidad material y tangible. Aunque las organizaciones conocen y parten de que, para que haya mayores resultados, respecto a los temas de violencia y de contención de la misma, necesitan de una mayor articulación entre las mismas organizaciones y un trabajo conjunto con el Estado (en sus tres niveles). Mientras que este trabajo conjunto y de ayuda mutua no se produzca, la violencia seguirá igual o irá a peor "debería haber más organización entre las asociaciones para poder entrar en las esferas de la sociedad y tengamos frutos (...) Hay muchas organizaciones que decimos que tenemos trabajo [conjunto], pero en realidad se ve muy poco, muy poco. Pero si tuviéramos apoyo de las autoridades habríamos de tener mejores resultados" (E10). Son las mismas organizaciones, las que señalan que los problemas de incrustación vertical y horizontal afecta el trabajo de contención y prevención de

25- "Lo que yo pude observar en la CNOP es que hay muchas "banditas" de jóvenes que se drogan, que no han intervenido el municipio, ni el Estado (E5), "Ya a la nueve de la noche ya no puedes salir" (E3).

26- Las organizaciones que residen dentro de CNOP son 35,42, 91, 138; y en La Obrera son E7, E32, E45, E55, E78, E83, E88, E98, E127, E128. Las OSC que trabajan dentro de CNOP son E4, E6, E11, E43, E51, E55, E61, E66, E71, E73, E86, E90, E92, E97, E135, E137, E138, E140, E141; mientras que lo hacen en La obrera E4, E5, E6, E11, E43, E46, E47, E51, E59, E61, E66, E69, E71, E73, E86, E90, E97, E105, E110, E135, E137, E138, E140, E141.

27- ||“hay una percepción de violencia muy alta, hay condiciones de violencia y de inseguridad. Pero además de eso, hay condiciones económicas y sociales que promueven el incremento de esa violencia” (E17). 
las violencias. Si estas redes de ayuda mutua fueran densas, el trabajo tendría mayores frutos.

Tales actividades van desde convivencia y apropiación ciudadana de lo público hasta espacios de vigilancia:

los vecinos se logren llevar con los vecinos, como cuando a lo mejor yo era chiquita, que todos se saludaban, que se salían a barrer las mujeres juntas. $\mathrm{O}$ sea, esos contextos ya no lo tienen. A la gente que le caiga el veinte, que estaríamos mejor vigilados y vigiladas si nos unimos de casa de en casa y pudiéramos hacer bastante. Si siento que se tiene hacer una... ya en México lo manejan en cuanto a robos, se hizo una alarma vecinal y la alarma vecinal ha dado resultados (E2).

Un discurso recurrente en los relatos consiste en recordar un pasado colectivo, donde había convivencia y confianza. Este pasado recordado es el inmediato y anterior a 2007, no se trata del paso de una sociedad rural a una urbana, como ocurrió en gran parte del siglo XX, sino del deterioro de los lazos de solidaridad y confianza producidos por el miedo y el contexto de violencia, a partir del gobierno de Felipe Calderón en 2006. Estos espacios de encuentro recurrentes permitían forjar los lazos de solidaridad y confianza: existía una comunidad. Sin embargo, la percepción de las organizaciones coincide en que, a través de la violencia, la comunidad y los lazos de solidaridad entre los vecinos han tendido a romperse. Medidas específicas propiciadas por la comunidad y la articulación de las organizaciones como "Alarma vecinal" pueden traer, de manera puntual, algo de la confianza perdida.

Según la Encuesta Estatal sobre Calidad de la Ciudadanía en Guerrero (2016), el 69.1\% de los ciudadanos chilpancigueños, mayores a 18 años, responden que no se puede confiar en la mayoría de las personas.

\section{Gráfico 1. Confianza en las personas}

\section{Confianza en las personas}

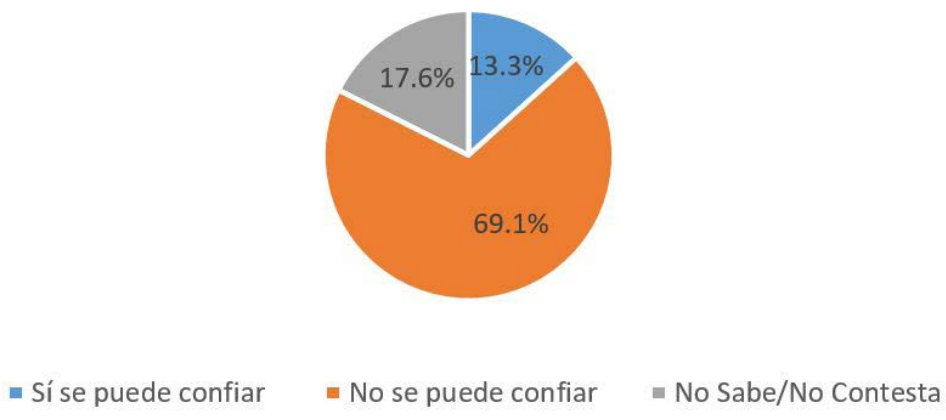

Fuente: elaboración propia a partir del EECCG (2016)

La distribución de la confianza a los distintos actores, según esta misma encuesta, es mayor hacia los maestros con un $59.4 \%$, seguido de las iglesias con un $47.2 \%$ y las organizaciones vecinales con un $39.2 \%$. Sin embargo, en los que menos se confía es en la policía, el 82.9\% de los encuestados dijo tener "poca o nada de confianza”. Después la poca confianza se deposita en el gobierno: el federal con un 79.5\%; el estatal con un $76.8 \%$ y el municipal con un $75.5 \%$. 
Gráfico 2. Distribución de la confianza por actor

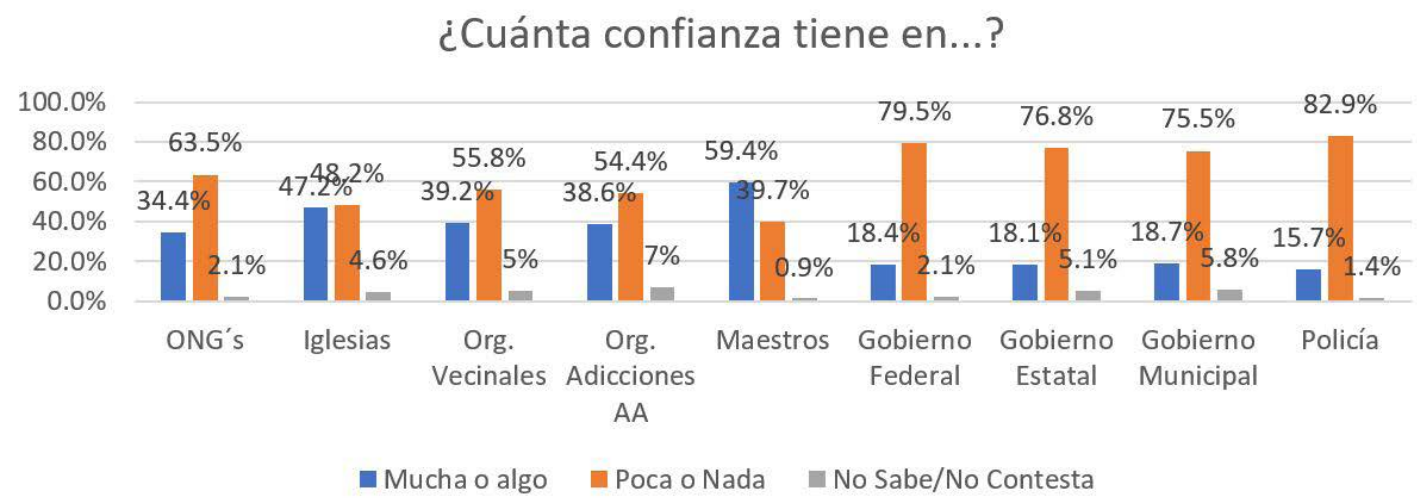

Fuente: elaboración propia a partir del EECCG (2016)28

Algo necesario y demandado por las propias comunidades de vecinos consiste en encontrase en espacios públicos, que puedan ser usados por la comunidad, que permitan verse a los ojos, escucharse y establecer diálogos con el objetivo de recuperar la confianza y el tejido social. La finalidad de estos espacios consiste en atravesar el miedo que produce la desconfianza hacia el vecino. Además, supone la ocupación del espacio para la pacificación del conflicto y también la ocupación del tiempo en la reconstrucción de los lazos y no en actividades ilegales.

hay algo que nos pedían mucho (...) 'dennos espacios para que nos veamos, para que unos a otros nos comuniquemos' (...) Un espacio en el que pudieran ser ellos los que hablaran. Pero agradecían mucho eso: un espacio en el que ellos, ellas vieran que pudieran estar más o menos seguros porque llevábamos la cobertura institucional y como que se olvidaran... Un espacio en el que una, dos o tres horas se olvidaran de su entorno (E8).

Dentro de los polígonos, específicamente, pero también en otras zonas de Chilpancingo, reclaman espacios de pacificación, donde las organizaciones hagan el papel de árbitro y de conciliación entre partes en lucha o lugares donde se han roto los lazos de solidaridad y confianza por los contextos de violencias. Es la propia sociedad la que innova las formas de comunicación y establece medios para estar seguros, como chats, silbatos y timbres. La intencionalidad de estas acciones es tener un espacio común, conocer al otro y establecer acuerdos dialogados (E9).

Apropiarse y ocupar los espacios públicos, además, supone atravesar el miedo, que tiende a recluirlos y aislarlos en lugares cerrados -normalmente en la casa-, y comenzar a articularse. Esto permitiría en el mediano-largo plazo que los lazos de confianza y solidaridad, fueran restaurados. En este sentido, las organizaciones coinciden en que el miedo y la falta de confianza en la comunidad constituyen el nodo de la problemática; y también de su posible solución: "No podemos ser tan insensibles a tanto 
dolor, y no podemos ponernos una venda a tanto dolor ajeno. Todos somos parte de una sociedad y si todos ponemos ese granito de arena, vamos a tener la vida digna que todos nos merecemos" (E6). Esto provoca que la sociedad no organizada no se quiera implicar en los asuntos o tema por su vida. En general, consideran que, si el miedo desapareciera y pudieran afrontar la situación en y desde la comunidad, mediante la esperanza, los lazos serían reparados y el tejido social, poco a poco, se iría recomponiendo: "considero que, si empezamos por partes y hacemos una sociedad unida, también, porque te voy a decir algo: hemos perdido la fe, la falta de amor y de la esperanza; y como ya está perdido todo eso, se pierden los valores" (E6).

La demanda de la población a la que atienden de "reencontrarse" o "volverse a juntar", que "puedan verse a los ojos", que puedan volver a confiar, es una demanda por la cohesión social. Sin embargo, las OSC no saben cómo mantener estos espacios de manera permanente y consideran que necesitan el apoyo del gobierno para que sea una medida sostenida en el tiempo: "Hay muchas organizaciones que decimos que tenemos trabajo, pero en realidad se ve muy poco, muy poco. El resultado es muy lento. Pero si tuviéramos apoyo de las autoridades y pues esto sería un beneficio a largo plazo, yo creo que habríamos de tener mejores resultados" (E11).

Existe, en general, una sensación más de resignación por ser algo que desborda la propia actividad y los servicios que ofrecen las OSC. El trabajo que realizan parte de que es parcial, que no soluciona la problemática. Para solucionarlo, las organizaciones coinciden en un trabajo conjunto, donde se pueda escuchar a las personas que experimentan violencia y donde la capacidad de respuesta y de la procura existencial y social del Estado sea mayor, con la ayuda de la sociedad civil. Así, sería posible recuperar, en cierto sentido, algo de la desconfianza quebrada:

La violencia ha incrementado su intensidad, hemos identificado cómo ha dañado de manera muy profunda el tejido social, los lazos comunitarios y sobre todo la confianza en la capacidad del Estado en poder reaccionar ante los problemas de violencia (...) lo que pudimos ver en Guerrero, una disposición muy grande de la gente de abordar los temas de seguridad, de dar sus opiniones y de tratar de construir sus propias propuestas de organización (E29).

La posibilidad de recuperar los lazos no está perdida, en el sentido en que es la propia sociedad la que muestra interés de vivir en paz y atajar los problemas ligados a las violencias. 
Gráfico 3. Pertenencia por tipo de organización

Pertenencia por tipo de organización social

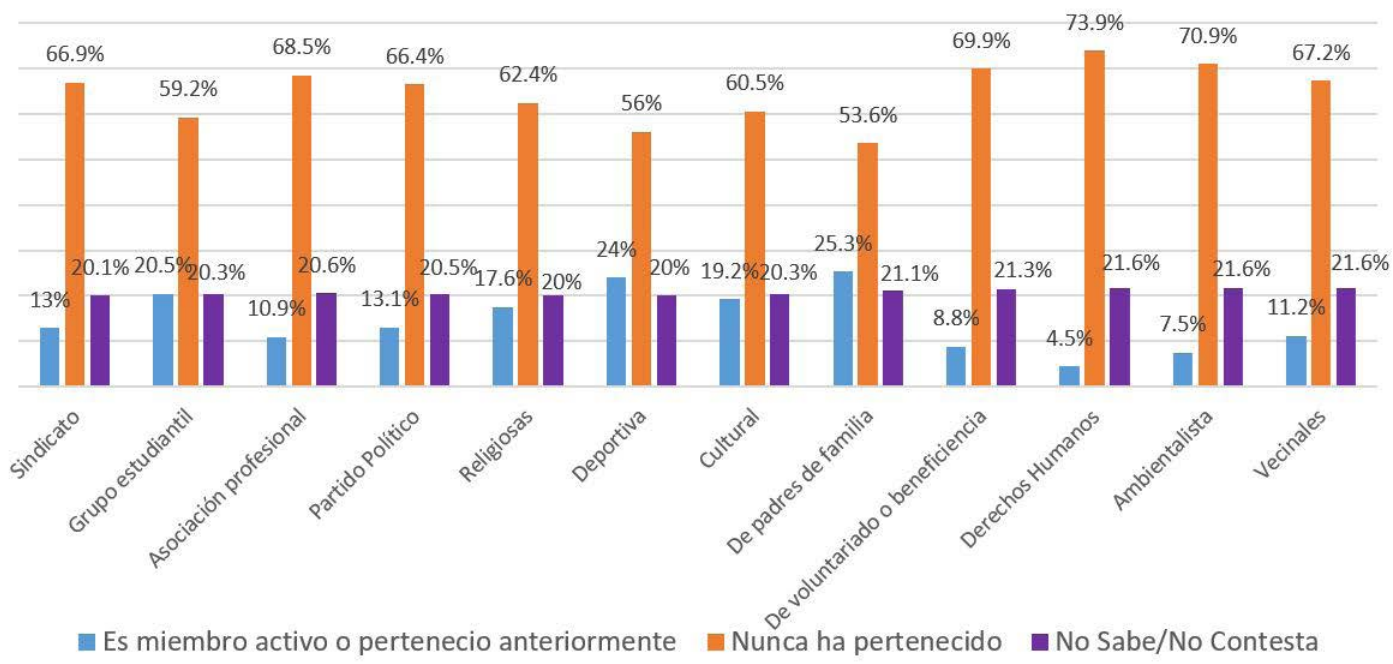

Fuente: elaboración propia a partir del EECCG (2016)

En cuanto a la pertenencia por tipo de organización, el ciudadano de Chilpancingo, que pertenezca o haya pertenecido a alguna asociación, tiene el porcentaje más alto en las asociaciones de padres de familia (25.3\%), seguido de las deportivas (24\%) y los grupos estudiantiles (20.5\%). Sin embargo, los porcentajes más altos de los que "nunca ha pertenecido" se corresponde con Derechos Humanos (73.9\%), las ambientalistas (70.9\%) y las asociaciones de voluntariado o beneficencia (69.9\%).

Las organizaciones coinciden en que el fenómeno de las violencias es multicausal o multifactorial, justo en esta caracterización reside su principal dificultad. ${ }^{29}$ Esta multiplicidad de condiciones en las que opera la violencia provoca que las OSC se sientan superadas por las circunstancias y las actividades que puedan llegar a realizar y que imposibilite que los mecanismos de cohesión social y de participación puedan ser reparados.

Ya ahora vemos que está inmiscuida en la violencia de género, violencia contra las mujeres, la violencia que provocan los grupos delincuenciales, aquellos llamados del crimen organizado. Vemos que también está la violencia económica, (...) la pauperización cultural y social que se vive ya de manera general. Es decir, los fenómenos

29- Según el Consejo Nacional de Población, en el Índice y grado de marginación de 2015, Guerrero obtuvo un grado de marginación "muy alto" y el primer lugar a nivel nacional en marginación (CONAPO, 2015: 19). En dicho índice, del total de los municipios de Guerrero, se muestra que (40.74\%) tuvieron un alto grado de marginación y (44.44\%) muy alto (CONAPO, 2015: 27). Esto supone que la mayoría de los municipios están entre un grado alto o muy alto de marginación. Los resultados particulares sobre Guerrero arrojan que (13.73\%) de la población de 15 o más años era analfabeta y (27.25\%) no había terminado la primaria; (13.03\%) de sus habitantes ocupaba viviendas sin drenaje ni sanitario; (2.40\%) residía en viviendas sin energía eléctrica; (15.64\%) no tenía agua entubada; (42.11\%) residía en viviendas con hacinamiento; (14.86\%) habitaba en viviendas con piso de tierra; (49.68\%) vivía en localidades con menos de 5 mil habitantes; y (53.29\%) ocupada ganaba hasta 2 salarios mínimos (CONAPO, 2015: 17). 
sociales se han venido modificando y nos hacen difícil un diagnóstico preciso. Sería determinar causas y consecuencias. Es mucho más complicado que antes. Algo que sí sabemos es que (...) es un fenómeno de muchos factores, de muchas causas y que en lo que sí hemos puesto el énfasis siempre es en que es necesario determinar cuál la característica del fenómeno de la violencia según los lugares (E8).

Son distintas violencias las que están operando simultáneamente, por lo que también esto dificulta su tratamiento por parte de la sociedad civil. Las organizaciones reconocen que es necesario un trabajo para que la violencia sea considerada como un problema social, político, cultural. Esto es así, porque confluyen distintos tipos de violencias y, en general, consideran que es difícil reconocerlas todas (violencia escolar, familiar, de género, feminicidios, económica, política, psicológica, física, homicidios, etc.). Asumen que les faltan herramientas y capacitación para abordarlas.

Las violencias han permeado de manera profunda. Están tan presentes en la vida cotidiana de la sociedad chilpancingueña, que la sociedad civil remarca como principal problema la "normalización" o "naturalización" de la violencia. Al parecer algo natural o normal, que se ha incrustado en las vidas de las personas, de las familias y los ciudadanos, es más difícil de combatir, porque no es experimentado como un problema público y político, sino individual y normalizado, donde se desarrollan estrategias individuales para afrontarlo, que tienden a aislar a los ciudadanos. Por el contrario, si el problema se convirtiera en social, con el apoyo de la sociedad civil, en político y público, la manera de afrontarlo sería colectiva y no estaría normalizada (E4). Esta naturalización afecta a lo que denominan como falta de "cultura de la denuncia" (E6). En este sentido, una entrevistada comenta:

tiene que ver con la naturalización: no ven la violencia, no la notan, no la perciben, es como si fuera, decía uno de ellos, es como si la violencia fuera el aire. Pues no. Uno no se da cuenta de que está respirando, no se pone a decir: 'ay, inspiro, espiro. Ellos lo ven como lo más natural, lo más normal. Entonces, no se lo plantean (E8).

De este modo, atribuyen las causas a un tejido social fragmentado y debilitado por la violencia. Los factores que producen, según las OSC, estas situaciones de violencia son: crimen organizado, pobreza, embarazos adolescentes, adicción a drogas, abandono o deserción escolar, violencia de género, violencia escolar, etc.

A menudo, las organizaciones consideran que las acciones que proponen no alcanzan a cubrir las necesidades del territorio donde se asientan, tampoco la población a la que se dirigen. Hay un acuerdo entre las organizaciones, más o menos tácito, de que las situaciones de violencias rebasan su campo de acción.

Coinciden en que se trata de recomponer el tejido social en un sentido amplio, donde las organizaciones puedan trabajar con el gobierno (municipal, estatal y federal), así como la sociedad. Se trata de una cohesión y una incrustación social (horizontal y vertical), donde la sociedad civil tendría un papel de intermediaria entre Estado y sociedad (vertical) y con otras organizaciones (horizontal):

Nosotros como organización esperamos que haya una mejor relación gobiernoorganizaciones, haya un mejor entendimiento, una mejor coordinación. Nosotros 
- Revista de Ciencias Sociales y Humanidades. ISSN-P: 0188-9834 ISSN-E: 2395-8669.

las organizaciones podemos aportar porque nosotros somos los que estamos más de cerca con la ciudadanía, con las comunidades rurales, sobre todo, y muy poco el gobierno, al menos el federal y estatal, al menos muy poco llegan (E10).

Un claro ejemplo de incrustación horizontal entre las organizaciones fue la solicitud de la $\mathrm{AVGG}^{30}$ en el 2016, y que fue el resultado del trabajo de las organizaciones ${ }^{31}$ : "cuando nosotras [el Frente de Alianza Feminista] presentamos la alerta, dijimos que el Estado estaba haciendo caso omiso ¿por qué omiso? Porque no estaba haciendo lo que la Ley le mandataba" (E19). En torno a la AVGG, se reunieron más de 26 organizaciones que se autodenominaron como Alianza feminista, "fuimos parte de las solicitantes de la alerta de género. Fue un proceso de integrar un expediente con datos para darle soporte a una solicitud de alerta de género, que la Ley establece que nosotras podemos ser las solicitantes" (E22). ${ }^{32}$ La solicitud se efectúa mediante el anclaje y la profundidad de las redes previas y recientes que tienen las propias organizaciones, tanto dentro como fuera del estado de Guerrero: "Habíamos invitado también a unas compañeras de Guanajuato que se llaman 'Las libres', porque ellas tenían la experiencia de la solicitud y nosotras queríamos saber cómo es el procedimiento. Llegaron ellas en esa reunión y nos explicaron cómo habían hecho, cómo habían logrado, los avances que tenían y decidimos presentar la solicitud" (E27). En el caso de la AVGG las organizaciones mediante la cohesión social e incrustación sociales consiguen que se apruebe la AVG. Este es el resultado de la lucha de las organizaciones para su establecimiento.

El principal problema que enfrentan las organizaciones para prevenir y contener la violencia, a excepción del caso de la AVGG, consiste en la falta capacitación y experiencia para abordar las violencias. Relatan que más que un fenómeno que puedan atender, es algo con lo que se encuentran después de realizar las actividades que tienen programadas. Es común que, al finalizar la actividad ${ }^{33}$-normalmente cursos de capacitación en alguna temática- pintado de uñas, construcción de piñatas para posadas, siembra de hortalizas, jabones, mezcales, elaboración de pizzas, papel picado, cajitas de regalo, cortinas, etc., algunas personas se acerquen para comentarles la situación de violencias que viven. Al término de la actividad, comentan de manera personal la problemática: una adicción, violencia de género, la necesidad de apoyos económicos para no caer en el crimen organizado, etc. La atención que dan las organizaciones también es personalizada, sin costo alguno, acompañan a denunciar, asesoran jurídica y psicológicamente (E14, E13).

En general, las organizaciones no trabajan con programas o planes establecidos para prevenir ni contener las violencias. La mayoría se encuentra con los temas de violencias cuando ha iniciado otro trabajo,

30-La Alerta de Violencia de Género puede ser declarada según la LGAMVLV, en su artículo 24, por tres causales: "I. Los delitos del orden común contra la vida, la libertad, la integridad y la seguridad de las mujeres, perturben la paz social en un territorio determinado y la sociedad así lo reclame; II. Exista un agravio comparado que impida el ejercicio pleno de los derechos humanos de las mujeres, y III. Los organismos de derechos humanos a nivel nacional o de las entidades federativas, los organismos de la sociedad civil y/o los organismos internacionales, así lo soliciten" (Cámara de Diputados del H. Congreso de la Unión, 2018: art. 24).

31- La solicitud de la AVGG fue admitida a trámite el 28 de junio de 2016 y fue aprobada casi un año después el 22 de junio de 2017.

32- La AVG es un mecanismo que sólo existe en México de política pública creado para la atención urgente y coordinada de los tres tipos de gobierno (federal, estatal y municipal) para la erradicación de la violencia feminicida y el agravio comparado.

33- Estas actividades tienen el propósito de "empoderar" a las mujeres o conseguir y autoabastecerse de recursos financieros legales dirigidos a la población en general. Las organizaciones entrevistadas desconocen el impacto de tales actividades, es decir, no han medido en indicadores sus resultados. 
normalmente cuando han destinado recursos estatales. Los programas con los que se han trabajado son: a) PRONAPRED (E8, E18, E22, E29), b) Vecino vigilante (E5, E12, E14, E16, E30), c) Escuela segura (E4), d) Mochila segura (E3), e) Ciudad de valores (E4). Otras organizaciones se centran en dar "pláticas" como forma de prevención, por ejemplo, en violencia de género (E6, E11, E21, E27) o sobre adicciones (E13). Hay programas heterogéneos, destinados principalmente a jóvenes que incluyen actividades culturales (como conciertos, break dance, grafitis poesía); y actividades deportivas como torneos, juegos de basquetbol, béisbol, fútbol (E1, E25, E30). También hay organizaciones que se enfocan en los proyectos productivos y, desde ahí, abordan los temas de violencia (E2, E3, E5, E7, E9, E12, E17, E18, E20, E25, E26, E28, E31, E34).

El trabajo que hacen la mayoría de las organizaciones, más que de prevención, es de contención de las violencias, por ejemplo, como canalizadoras a otras organizaciones o a instancias gubernamentales para resolver las problemáticas en torno a las violencias sufridas (E11, E14, E15, E16, E17, E18, E19, E21, E23, E27). Esto es, las organizaciones que no se dedican directamente a temas de prevención suelen tener la información para canalizar en casos de violencia, en atención a víctimas (en temas jurídicos, psicológicos), etc. Sin embargo, dos organizaciones no canalizan, por considerar que no saben del tema y no cuentan con información actualizada. También aseguran que la población sabe qué es lo que debe hacer "por lo regular las líderes de su comunidad que son mujeres, se han enfrentado al abuso de sus maridos y eso, pero como no es mi ámbito yo ya no me inmiscuyo más allá de cómo salieron de ahí o qué les pasó (...) ellas están bien enteradas a dónde ir" (E31). Estas dos organizaciones no trabajan contención ni prevención de las violencias (E30, E31).

En este sentido, las OSC, en general, no se dedican a prevenir en temas de violencia, más bien saben que se encontrarán con ello, pero reconocen no tener la capacitación, ni herramientas, ni los recursos suficientes para atacar la problemática. Se encuentran con temas de violencia al aplicar otras actividades.

Sin embargo, no desconocen el problema, más bien, ocurren al menos cuatro tipos de situaciones: 1) tienen proyectos aprobados con recursos en otros temas; por ejemplo, proyectos deportivos y culturales (E1, E5, E8, E9); 2) sienten miedo al abordar de manera frontal la situación de violencia, al faltar un clima generalizado de confianza (E3, E5, E8, E22, E23, E26, E27, E31, E34); 3) consideran que no habría público interesado en acudir o éste podría tener miedo, al sentirse expuesto. Este miedo podría extenderse a las OSC, que consideran pueden ser vulneradas, al estar señaladas por el crimen organizado y las autoridades (E8, E11, E13); y 4) no están preparados para abordar una problemática tan compleja, a pesar de conocer que es el principal problema que tiene la población a la que van a atender (E7, E31, E32, E33). Estas opciones no son excluyentes, las OSC pueden estar experimentando más de una situación. Por otro lado, las organizaciones no conocen el impacto de sus propias actividades, lo que las inhibe. Las organizaciones consideran deberían establecer indicadores para medir la implementación de las prevenciones y contenciones de las violencias.

Si bien son pocas organizaciones que se dedican a temas de prevención, la mayoría que previene desarrolla actividades enfocadas en "pláticas" de prevención en violencia de género (E6, E11, E21, E27) y sobre prevención del delito, tipos de violencia y recomendaciones para ocupar y rescatar espacios públicos "no estar en malas cosas" ni estar aislados (E3, E10, E13, E14, E15, E19, E20, E24, E32). En este sentido, un entrevistado comenta: 
como tipo pláticas, no sólo la violencia contra la mujer, la violencia contra jóvenes, contra discapacitados. Llevamos nosotros miembros especialistas en lo que es violencia, que nos lo presta la Institución (...) y además de que se les da la plática, se les dan números de instituciones donde ellos pueden acudir por cualquier tipo de violencia (E6).

El objetivo de estas pláticas consiste en que las personas beneficiadas tomen consciencia y que, en algún momento, puedan cambiar su experiencia. En general son "pláticas" de sensibilización: "a través de reuniones, a través de concientización a la población, a través de comités de colonias. Trabajamos con ellos y pues bueno, hacemos pláticas con los colonos cuando ellos se reúnen para tomar algunos acuerdos de beneficio de sus colonias, y pues esto sería un beneficio a largo plazo" (E10). En estos casos, la población no está segmentada ni tampoco el tipo de "plática" que se ofrece. Se trata de explicarles la realidad en la que viven y los recursos legales que tienen a su alcance en caso de que sean víctimas de algún tipo de delito: "La prevención yo creo que no la estamos trabajando. Nadie está trabajando este tema, que además es el más importante. Específicamente nadie se ocupa de la prevención (...) debemos empezar por informar a la sociedad, por sensibilizar, por reeducar a los hombres, a las mujeres" (E11).

Un problema que enfrentan es el de no poder mantener los programas o actividades en el tiempo. Reconocen que hacen esfuerzos puntuales y que, aunque muchas veces, quieren continuar a mediano o largo plazo, no tienen recursos suficientes o, si se trata de un programa propuesto por el gobierno, la duración máxima es de 12 meses. Los proyectos son aprobados por tiempos cortos o medianos (en general, de 6 a 12 meses).

Hay, sin embargo, dos organizaciones (E8, E29) que destacan en temas de trabajo de prevención, no sólo por centrarse en dar pláticas, sino más bien capacitan y buscan actores de paz, que consigan mediar en situaciones de conflicto. Al respecto:

Nuestra organización como tal buscaba compartir herramientas y desarrollar habilidades en grupos multi-actor de la comunidad de Chilpancingo para articularlos en una red que pudiera asumirse a gente de paz dentro del municipio y que, a partir de una dinámica de vinculación se pudieran desarrollar distintas prácticas que enfrentaran la situación de violencia [como] estas expresiones no letales que se pueden ubicar en el deterioro de las relaciones interpersonales, en la desconfianza que existen a las autoridades, con los diferentes problemas de convivencia, incluso de comunicación (E29).

Para ello hay un trabajo de mapeo para ubicar posibles actores que puedan hacer de "bisagra" entre las comunidades y las autoridades (E8, E29). Estas organizaciones establecieron un proceso de capacitación y formación a la ciudadanía, mediante también "actores clave", que establecieran un puente entre la ciudadanía y la sociedad civil, y entre esta última y el Estado. Así, se trataba de "un mecanismo de prevención comunitaria, que esto era en el marco del Programa Nacional de Prevención de la Violencia" (E29), con el objetivo de crear redes ciudadanas que sirvieran de apoyo para la prevención y contención de las violencias (E8).

Estas dos organizaciones tienen un abordaje más a mediano y largo plazo, al formar actores de paz que puedan mediar en situaciones de conflicto o antes de que se produzca el conflicto y que tiene una duración 
mayor de lo que dura la actividad. La intención de capacitar y que sea la propia comunidad la que tenga herramientas para disminuir o mediar en disputas hace que no sea una sola plática, aislada y puntual, sino un trabajo que busca generar ciertos efectos que, por otro lado, no han podido ser comprobados.

Uno de los entrevistados señala que al ser tan recurrente y al atravesar tanto las vidas de la comunidad, la violencia tiene un carácter de "crónico":

podemos identificar como "violencia crónica" y nos referíamos a estos espacios donde la violencia, el número de homicidios, de expresiones violentas, sobre todo de expresiones letales se han mantenido durante tanto tiempo en el mismo lugar y han incrementado su intensidad, que hemos identificado como ha dañado de manera muy profunda el tejido social, los lazos comunitarios y sobre todo la confianza en la capacidad del Estado en poder reaccionar ante los problemas de violencia (E29).

La violencia o las violencias no son algo abstracto además que sólo sufran las personas a las que se dirigen, sino que forman parte de su práctica laboral, asociativa y de voluntariado. Como ha sido señalado en otras investigaciones De León y Velásquez (2012), la sociedad civil se encuentra entre dos fuegos, entre el estado y el crimen organizado. Así, reciben amenazas por ambas partes. Algunas organizaciones han recibido amenazas directas por parte del gobierno (E3, E8, E22, E34) para que paren las actividades que están realizando, mediante llamadas telefónicas han exhortado a finalizar con lo que estaban haciendo. Es el caso de una organización que tuvo que parar sus actividades e irse a una segunda línea de incidencia, porque sufrió amenazas personales y familiares, incluso, han tenido que desplazarse dentro de la ciudad o a otras ciudades de la República:

Me amenazó directamente [alguien cercano] del Gobernador Héctor Astudillo Flores $^{34}$, me llamó a mi teléfono personal (...) teníamos una relación cordial, nos conocíamos, (...) me dijo directamente que qué chingaderas eran esas, qué andaba haciendo, que si no tenía miedo y si no pensaba en mis hijos (E34).

Otras organizaciones han sentido un hostigamiento continuado por parte del gobernador del Estado, aunque esto no había pasado anteriormente, ni siquiera con otros gobiernos prisitas:

Todo gobierno que no hace bien las cosas, no quiere que las organizaciones observen. Entonces, tienen una actitud hacia las organizaciones de apestadas (...), al menos yo no había participado en un espacio donde me sintiera tan hostigada como organización. (...). Hemos trabajado con otros gobiernos priístas y nunca he sentido este hostigamiento de esta naturaleza (E22).

En general, sienten amenazas por defender causas sociales y políticas, saben que está en riesgo su vida: "nos amenazan y nos dicen: 'tú ya párale a ese tema"' (E8). 
Sin embargo, las OSC también han sido amedrentadas, acosadas y amenazadas por el crimen organizado (E5, E8, E23, E26, E27, E31). En ocasiones, sienten que están entrando a un territorio que pertenece al crimen organizado y que cuenta con la complicidad gubernamental, que conoce la situación y no usa medidas alternativas. Algunas organizaciones han recibido amenazas tanto personales como a sus familiares y han decidido abandonar el estado, con los costos personales, laborales y familiares de lo que significa desplazarse por haber recibido amenazas:

La amenazaron a ella, igual que a su pequeña hija. Se tuvo que ir a Cuernavaca, Morelos (...) después yo tuve alguna amenaza también aquí en mi propia casa. (...) Estábamos acompañando algunos casos que los hicimos públicos en una conferencia de prensa y después de esa conferencia de prensa, es cuando se vinieron las amenazas. Primero hacia ella y posteriormente se vino la amenaza hacia mi persona (...) Fueron dos amenazas distintas (E27).

En este sentido, realizar los trabajos en algunas colonias, sobre todo, marginales, como pueden ser La Obrera y la CNOP supone un miedo personal y dificultad para realizar los trabajos. Las organizaciones recurren a distintas estrategias para adentrarse a los territorios: 1) ponerse un horario de entrada y salida a las colonias (E8; E14; E22); 2) cubrirse el rostro para no ser identificado no sólo por el crimen organizado, sino también por el gobierno o exigir en redes (E34).

Las dificultades para llegar a los territorios en conflicto son tan palpables que, en ocasiones, si quieren introducirse en dichas colonias deben usar a alguien que haga de "portero" y establezca el nexo o vínculo para permitirles entrar en los polígonos, para ganarse la confianza a la comunidad o sociedad a la que van a atender (E13, E26, E28). No siempre son las propias organizaciones las que establecen contacto. A veces, las propias colonias buscan organizaciones que puedan reunirles y darles alguna capacitación o plática en torno a la violencia (E27).

\section{Conclusiones}

Este trabajo se preguntó por el modo en que las organizaciones de la sociedad civil chilpancigueña contienen y previenen las violencias. Las conclusiones a las que se llega después de un análisis mixto son que las actividades de cohesión e incrustación sociales que han realizado las organizaciones son iniciales. Se trata de trabajos que están comenzando, por dos motivos principales: 1) por el desborde que expresa la sociedad civil organizada a la que se ha entrevistado para tratar los temas por desconocimiento, por riesgo y miedos personales y organizacionales; y 2) porque las actividades, en el mejor de los casos, duran un año por la dependencia de recursos que tiene la sociedad civil respecto a los programas estatales, por lo que no tienen continuidad. La duración de las actividades es importante para que haya continuidad y porque el trabajo de prevención debe ser a mediano y largo plazo. La poca duración de las actividades, que puede ir de días, semanas o meses, imposibilita el impacto de las mismas, construyendo indicadores que puedan analizar la percepción de la problemática antes y después de aplicar las actividades, por ejemplo, con un "pretest" y "postest". Incluso, saber cuáles son los ajustes a tener en cuenta para repetir la 
actividad. En este sentido, a excepción de dos organizaciones que han realizado capacitaciones $(\mathrm{E} 8,29)$, las organizaciones hacen trabajo de contención. A menudo, reconocen no poseer la capacitación ni las herramientas adecuadas para enfrentar el problema de las violencias y contener y prevenir el fenómeno que consideran multifactorial y multicausal.

Las actividades que demandan por la apropiación del espacio público y, desde ahí, la reconstrucción de la comunidad mediante la cohesión e incrustaciones sociales, son actividades: a) de contención, en el sentido en que el tiempo que estén ahí no están insertos en temas de violencias. También sirve de canalización de violencias y de cuidado de otros; y b) reactivas en el sentido de Serbin (2008), no se trata de prevenir porque las organizaciones reconocen estar lejos de poder aplicar la prevención por falta de capacitación y también porque consideran que para poder llegar a la prevención es necesario reconstruir el tejido social.

Siguiendo a De León y Velásquez (2012), las violencias, además, no son fenómenos alejados de la experiencia y vivencia de las organizaciones. Éstas sufren la violencia en las colonias en las que trabajan. Pero también sufren la violencia directa o más o menos velada por parte del Estado. A menudo, las violencias se expresan en forma de amenaza, cuidando sus horarios de entrada y salida, cubriendo su rostro, buscando un contacto dentro de la colonia que les abra el espacio para poder realizar las actividades.

En general, las organizaciones reconocen que el trabajo de prevención no se realiza. En el mejor de los casos, dan "pláticas" para sensibilizar a la población en la problemática, que reconocen está naturalizada, normalizada y se ha vuelto crónica por su intensidad. Esta normalización junto con la intensidad del fenómeno no ayuda a tratarlo como un problema social, político ni público que requiera del trabajo colectivo. Las estrategias para afrontar las violencias suelen ser individuales, también las que sufren las propias organizaciones. Sin embargo, existen dos organizaciones (E8, E29) que han realizado trabajos de prevención, formando y capacitando a "actores clave" que, a su vez, permita la construcción de redes en la sociedad y que hagan de intermediarios con la sociedad civil y el Estado.

La desconfianza produce que la relación entre la sociedad, sociedad civil y gobierno sea problemática. A menudo, hay obstáculos incluso para poder desarrollar las actividades al interior de las colonias, por ejemplo, muchas de ellas trabajan otros temas, a sabiendas de que los principales problemas que se van a encontrar son los relacionados a las violencias (contención y prevención). En el mejor de los casos, hacen de canalizadoras ante las autoridades $u$ otras organizaciones, donde puedan recibir apoyo psicológico, monetario y/o jurídico.

Esta desconfianza también produce aislamiento y miedo, por lo que las estrategias colectivas, demandadas por la propia sociedad y confirmadas por la sociedad civil, de poner en común los problemas de violencias y hacer comunidad desde esta apuesta en común, son en parte desplazados por la propia desconfianza y el miedo. Los vínculos de solidaridad, de apoyo mutuo que definen la categoría de cohesión social, son más el recuerdo de un pasado cercano (anterior al gobierno de Felipe Calderón), y el deseo de un presente y futuro próximos, como un horizonte, que el resultado de un trabajo tangible y material realizado por las propias organizaciones.

Las organizaciones consideran que, si el trabajo que realizaran fuera conjunto tanto con otras organizaciones, como con el propio Estado en sus tres niveles, los resultados serían más positivos y, de algún modo, entre los distintos actores podría darse esta contención y prevención de la violencia. 
La mayoría de las organizaciones del directorio no trabajan en los polígonos señalados por el PRONAPRED como focos rojos. Estas colonias, en principio, reciben a través de las organizaciones recursos públicos. Sin embargo, las organizaciones que han trabajado con el PRONAPRED lo han hecho a título individual, que son determinadas personas que, por su trayectoria, sobresalen en las organizaciones. Se desconoce dónde han ido a parar dichos recursos y el uso que se ha hecho de ellos. Esto podría ser abordado en otro trabajo de investigación.

Un hallazgo de esta investigación es el trabajo conjunto de las organizaciones para la solicitud e instauración de la AVGG: es el principal logro de las organizaciones de mujeres, de derechos humanos y feministas que se articulan para declarar un mecanismo urgente de política pública como es la Alerta. Es la Comisión Nacional para Prevenir y Erradicar la Violencia contra las Mujeres (CONAVIM) la que termina declarando la Alerta como instancia federal, pero se trata de una iniciativa de la sociedad civil.

$\mathrm{Al}$ igual que otros trabajos realizados, éste supone un aporte del trabajo que realizan las organizaciones de la sociedad civil en contextos urbanos de violencia, hasta el momento de la revisión, no se ha realizado un estudio semejante para el caso de Chilpancingo (Valle, 2019; Serrano y Modrego, 2012; Aziz, 2011; González, 2009; Castillo, 2009; Serbin, 2008; Zúñiga, 2007).

\section{Referencias}

Agren, David. 2015. Bad, old Acapulco. https://archive.macleans.ca/issue/20150511 (4 de abril de 2019). Aguirre, Irma. 2004. Del silencio a la palabra. La experiencia de las lideresas indígenas de Xochistlahuaca, Guerrero. Feminismo/s, Revista del Centro de Estudios sobre la Mujer de la Universidad de Alicante, (3): 101-116.

Ansolabehere, Karina y Paula Valle. 2017. The political-legal representation circuit of human rights politics. En Intermediation y Representation in Latin America, editado por Gisela Zaremberg, Valeria Guarneros y Adrán Gurza. Inglaterra: Palgrave, 159-180.

Aranda, José. 2008. Reflexividad y legitimación de problemas sociales: el caso de la Red de Organizaciones Ambientalistas de Zihuatanejo. Convergencia, Revista de Ciencias Sociales, 15 (46): 169-193.

Aziz, Alberto. 2011. Violencia y destrucción en una periferia urbana. El caso de Ciudad Juárez, México. Gestión y Política Pública, XXI: 227-268.

Barba, Carlos. 2011. Revisión teórica del concepto de cohesión social: hacia una perspectiva normativa para América Latina. En Perspectivas críticas sobre la cohesión social: Desigualdad y tentativas fallidas de integración social en América Latina, coordinado por Carlos Barba y Néstor Cohen. Buenos Aires: CLACSO, 67-86.

Cámara de Diputados del H. Congreso de la Unión. 2018. Ley general de acceso de las mujeres a una vida libre de violencia. http://www.diputados.gob.mx/LeyesBiblio/pdf/LGAMVLV_130418.pdf(28/10/2019). Canabal, Beatriz. 2015. Presencia social de la población indígena en Acapulco. Rutas de campo, (6): 45-51. 2003. Mujeres indígenas y democracia. Una primera reflexión desde la Montaña de Guerrero. La ventana, Revista de Estudios de Género, 2 (18): 210-253.

. (s/f). Mujeres indígenas migrantes: el caso de la región de la Montaña de Guerrero,

México. https://ddhhmigraciones.files.wordpress.com/2018/06/cristiani.pdf (3 de abril de 2019). 
Cattan, Nacha. 2011. Decapitated bodies in Acapulco spotlight drug war's toll on tourism. https://www. csmonitor.com/World/Americas/2011/0109/Decapitated-bodies-in-Acapulco-spotlight-drug-war-stoll-on-tourism (3 de abril de 2019).

Castillo, Nemesio. 2009. Capital social y nivel de cohesión social en Ciudad Juárez. En Diagnóstico sobre la realidad social, económica y cultural de los entornos locales para el diseño de intervenciones en materia de prevención y erradicación de la violencia en la región norte: el caso de Ciudad Juárez, Chihuahua, Laurencio Barraza (Coord.). México: CONAVIM- SEGOB, 296-323.

Comisión Económica para América Latina y el Caribe (CEPAL). 2007. Cohesión social. Inclusión y sentido de pertenencia en América Latina y el Caribe. Santiago de Chile: CEPAL-SEGIB.

Consejo Nacional de Población (CONAPO). 2015. Capítulo 2. Marginación por entidad federativa, 2015. https://www.gob.mx/cms/uploads/attachment/file/159053/02_Capitulo_2.pdf (3 de abril de 2019). 2015. Capítulo 3. La marginación en los municipios, 2015. https:/www.gob.mx/cms/uploads/ attachment/file/159054/03_Capitulo_3.pdf (3 de abril de 2019).

De León, Isaac y Elkin Velásquez. 2012. Cohesión social, confianza y seguridad en América Latina: un estudio exploratorio. En Violencia y cohesión social en América Latina, Francisco Díaz y Patricio Meller (Comp.). Santiago de Chile: CIEPLAN, 49-104.

Fernández, Flory. 2002. El análisis de contenido como ayuda metodológica para la investigación. Revista de Ciencias Sociales, 2 (96): 35-53.

Figueroa, Carlos y Lorena Martínez. 2013. The Ejército Popular Revolucionario. Occupying the Cracks in México's Hegemonic State. Latin American Perspectives, 40 (192): 153-164.

Forsthoff, Ernest. 2015. Estado de derecho en mutación. Madrid: Tecnos.

2013. El Estado de la sociedad industrial. Madrid: Centro de Estudios Políticos y Constitucionales.

Gamlin, Jennie y Sarah Hawkes. 2018. Masculinities on the Continuum of Structural Violence: The case of Mexico's Homicide Epidemic. Social Politics, 25 (1): 50-71.

González, Rosa. 2009. Violencia y capital social en la zona metropolitana de Tijuana. En Diagnóstico sobre la realidad social, económica y cultural de los entornos locales para el diseño de intervenciones en materia de prevención y erradicación de la violencia en la región norte: el caso de Tijuana, Baja California Norte, Silvia López (Coord.). México: CONAVIM- SEGOB, 139-172.

Gutiérrez, Gustavo. 2007. Contaminación simbólica: una forma más de violencia sociocultural. El Cotidiano, 22 (143): 35-40.

Herrera-Laso, Luis. 2012. Factores que propician la violencia y la inseguridad: apuntes para una estrategia integral de seguridad pública en México. Ciudad de México: Grupo Coppan SC.

Instituto Nacional de Estadística y Geografía (INEGI). 2019. Encuesta Nacional de Seguridad Pública Urbana (septiembre 2019). https://www.inegi.org.mx/contenidos/saladeprensa/boletines/2019/ensu/ ensu2019_10.pdf (15 de diciembre de 2019).

Instituto Electoral y de Participación Ciudadana del Estado de Guerrero (IEPC-Gro), Instituto Internacional de Estudios Políticos Avanzados Ignacio Manuel Altamirano (IIEPA-IMA). 2017. Informe sobre la calidad de la ciudadanía en Guerrero. México: IEPC-Gro.

Jasso, Carmina. 2013. Percepción de inseguridad en México. Revista Mexicana de Opinión Pública, (15), 13-29. 
Jusidman, Clara, Rosa Rubalcava, Osiris Marín, Ingrith Carreón y Ana Stern. 2011. Nota metodológica para el diagnóstico territorial de las causas sociales de las violencias. México: INCIDE Social.

King, Gary, Sidney Verba y Robert Keohane. 2000. El diseño de la investigación social: la inferencia científica en los estudios cualitativos. España: Alianza Editorial.

Ley, Sandra. 2014. Citizens in Fear: Political Participation and Voting Behavior in the Midst of Violence. Tesis de doctorado, Durham: Duke University.

Llana, Sara. 2006. Drug-trade violence grips Acapulco. https://www.csmonitor.com/2006/0914/p06s01woam.html (4 de abril de 2019).

López, Fernando. 2002. El análisis de contenido como método de investigación. Revista de Educación, (4): 167-179.

Lunecke, Alejandra y Juan Carlos Ruiz. 2007. Capital social y violencia: análisis para la intervención en barrios urbanos críticos. En Seguridad y violencia: desafíos para la ciudadanía, Lucía Dammert y Liza Zúñiga (Eds). Santiago de Chile: Flacso-Chile, 225-252.

Martínez, Lorena. 2012. La comunidad como origen del poder. El surgimiento de formas de organización alternas. Visioni LatinoAmericane è la rivista del Centro Studi per l>America Latina, (7): 30-57.

Muggah, Robert y Katherine Aguirre. 2018. Citizen security in Latin America: facts and figures. https:// igarape.org.br/wp-content/uploads/2018/04/Citizen-Security-in-Latin-America-Facts-and-Figures.pd f?fbclid=IwAR2yDzRySmMZVKeZkkCraxisWUaownnve3-vJRUuGg8Gmfik3O9-nkaS_zg_(3 de abril de 2019).

Niño, Naú. 2008. Ambiente de la isla Roqueta de Acapulco Guerrero, México. El periplo sustentable, (14): $5-25$.

Observatorio Ciudadano Nacional del Feminicidio (OCNF). 2018. Informe implementación del tipo penal de feminicidio en México: Desafíos para acreditar las razones de género 2014-2017. https://observatoriofeminicidio.files.wordpress.com/2018/05/enviando-informe-implementaciocc81n-del-tipopenal-de-feminicidio-en-mecc81xico-2014-2017-1.pdf_(4 de abril de 2019).

Olvera, Alberto. 2007. Notas sobre la participación ciudadana desde la óptica de las Organizaciones de la Sociedad Civil. https://controlatugobierno.com/archivos/bibliografia/olvera1.pdf (3 de abril de 2019). Polanyi, Karl. 2012. La gran transformación. México: FCE.

Quintero, Dulce y José Domínguez. 2011. Mesa 5: Medio ambiente y participación local. Movimientos ciudadanos y la lucha ambiental en Guerrero. Ponencia presentada en Memorias X Congreso Anual de Investigación sobre Sociedad Civil. Sociedad y Ciudadanía en el cambio social. Análisis y perspectivas a 10 años del Congreso de Investigación, Ciudad de México.

Ríos, Brenda. 2008. Hay tantas maneras de matarse los unos a los otros. Metapolítica, (61): 89-91.

Rivera, Rocío. 2015. Violence in urban Mexico: a municipal analysis of state capacity and competition among drug trafficking organizations. Tesis de doctorado, Miami: University of Miami.

Sánchez, Evangelina y Claudia Rangel. 2008. El sistema de seguridad como forma alternativa de justicia. La experiencia de los me' phaa y nuu savi de la Costa-Montaña de

Guerrero. En Procesos de democratización en México: balance y desafíos más allá de la alternancia, compilado por Diana Favela. México: UNAM-Centro de Investigaciones Interdisciplinarias en Ciencias y Humanidades, 87-104. 
Seguridad, justicia y paz. Consejo ciudadano para la seguridad pública y la justicia penal A.C. 2019. La violencia en los municipios 2018. México. http://seguridadjusticiaypaz.org.mx/files/La-violencia-en-losmunicipios-de-Me\%CC\%81xico-2018.pdf_(4 de abril de 2019).

Serrano, Claudia y Félix Modrego. 2012. Cohesión territorial: la dimensión ausente del desarrollo en América Latina. En Violencia y cohesión social en América Latina, Francisco Díaz y Patricio Meller (Comp.). Santiago de Chile: CIEPLAN, 235-278.

Serbin, Andrés. 2008. La sociedad civil ante la violencia y los conflictos en América Latina y el Caribe. Pensamiento Iberoamericano, (2): 141-162.

Sorj, Bernardo y Eugenio Tironi. 2007. Cohesión social en América Latina: un marco de investigación. Pensamiento Iberoamericano, (1): 105-127.

Triana, Jorge. 2017a. Percepción de seguridad en polígonos geográficos prioritarios en Acapulco. Espiral, 24 (70): 221-249.

.2017b. Conceptos, enfoques y teorías de prevención de la violencia y delincuencia. Revista Altamirano, (47): 89-101.

Valle, Paula. 2019. La violencia en Acapulco desde la sociedad civil: mecanismos de cohesión y contraloría social. Intersticios Sociales, (18): 169-212.

Valle, Paula. En prensa. El papel de la sociedad civil acapulqueña y chilpancigueña en la prevención y contención de las violencias: análisis comparativo

Valles, Miguel. 1999. Técnicas cualitativas de investigación social. Reflexión metodológica y práctica profesional. España: Síntesis Sociológica.

Vilchis, Gretha, María Díaz, Ricardo Soto, Gabriela Bernal, Marisol Alcocer, Elia Moreno, Valeria López y Anel Ortega. 2016. Informe del grupo de trabajo conformado para atender la solicitud de Alerta de Violencia de Género contra las Mujeres en ocho municipios del Estado de Guerrero. https://www.gob. mx/cms/uploads/attachment/file/127431/Informe_AVGM_Guerrero.pdf_(4 de abril de 2019).

Zúñiga, Liza. 2007. Participación comunitaria en prevención del delito: experiencias de América Latina y Europa. En Seguridad y violencia: desafíos para la ciudadanía, Lucía Dammert y Liza Zúñiga (Eds). Santiago de Chile: Flacso-Chile, 135-188. Chile: Flacso-Chile. 
nóesis Determinantes de la ocupación hotelera de los principales... / Volumen 29, Número 58-1 agosto - diciembre 2020 www.revistanoesis.mx 84

\title{
DETERMINANTES DE LA OCUPACIÓN HOTELERA DE LOS PRINCIPALES DESTINOS DE SOL Y PLAYA DE MÉXICO
}

\author{
Determinants of hotel occupancy of the main destinations \\ of sun and beach in Mexico
}

Reyna María Ibañez Pérez ${ }^{1}$ Marco Antonio Almendarez-Hernández², Ismael Sánchez-Brito ${ }^{3}$

Fecha de recepción: 3 de septiembre de 2019.

Fecha de aceptación: 9 de enero de 2020.

1- Nacionalidad: Mexicana. Grado: Doctorado en Economía. Adscripción: Universidad Autónoma de Baja California Sur.. Correo electrónico: ribanez@uabcs.mx. (D) ORCID: http://orcid.org/0000-0002-9392-3490

2- Nacionalidad: Mexicana. Grado: Doctorado en Economía. Adscripción: Universidad Autónoma de Baja California Sur. Correo electrónico: malmendarez@cibnor.mx. (iD ORCID: http://orcid.org/0000-0002-6017-3929

3- Nacionalidad: Mexicana. Grado: Doctorado en Ciencias Marinas y Costeras. Adscripción: Universidad Autónoma de Baja California Sur. Correo electrónico: isanchez@cibnor.mx. (D) ORCID: http://orcid.org/0000-0003-3811-0814 